\title{
Effect of microencapsulated plant extracts on mosquito repellency
}

\author{
Mamta Rana*, Saroj S. Jeet Singh and Saroj Yadav \\ Department of Textile and Apparel Designing, CCS Haryana Agricultural University, Hisar - 125004 (Haryana), INDIA \\ *Corresponding author. E-mail: chauhan.mamta1986@gmail.com
}

Received: December 19, 2016; Revised received: April 26, 2017; Accepted: October 2, 2017

\begin{abstract}
Mosquitoes are the most important single group of insects in terms of public health importance. Mosquitoes not only cause nuisance by their bites but also transmit deadly diseases. The activity of mosquitoes is affected by climate, light and temperature. In tropical areas like India, the population of mosquitoes is found huge day by day. Repeated use of synthetic insecticides for mosquito control has disrupted environment as well as human health. To overcome this problem, plant derived compounds may be the better alternate over synthetic insecticides. To enhance the health and hygiene qualities by means of use of medicinal plants through effective application technique on textiles, marigold (petals) and nirgundi (leaves) methanol extract was used as mosquito repellent finish on $100 \%$ woven cotton. For applying mosquito repellent finish on fabric, complex coacervation technique of microencapsulation was used through pad-dry-cure method. Finished cotton samples were tested against Anopheles stephensi by using laboratory cage method for their efficacy and durability to washing and sun-drying as per standard test methods. Marigold (petals)and nirgundi (leaves) extract finished fabric samples showed 96 and $94 \%$ repellency respectively after 60 minutes of observation. It remained $56 \%$ and $54 \%$ (after 15 washes) and 54 and $52 \%$ (after exposure in sun for 3 hours) by the application of marigold and nirgundi extracts respectively. Hence, microencapsulation technique on selected cotton textile proved effective to repel mosquitoes up to acceptable level according to WHO (1996).
\end{abstract}

Keywords: Marigold, Microencapsulation, Mosquito repellent finish, Nirgundi, Pad-dry-cure method

\section{INTRODUCTION}

Mosquitoes are most common and widely existed harmful insect. The most common dreadful diseases associated with mosquitoes are malaria, yellow fever, filariasis, schistosomiasis, japanese encephalitis (JE) and dengue hemorrhagic fever. According to Centers for Disease Control, mosquitoes alone transmit disease to more than 700 million persons annually. Malaria kills 3 million persons each year, including 1 child every 30 seconds. At present, the more successful measures to decrease the malaria are by personal protection and control of the vectors. Synthetic insecticides are most common to control these vectors but due to harmful effects i.e. unpleasant smell, oily feeling to some users and potential toxicity on living things, are causing irreversible damage to the eco-system, as some of them are non-degradable in nature. Hence, these are avoiding by people. To reduce the risks of harmful insecticides, medicinal plants are used by the textile researchers for personal protection from mosquito bites as well as plants are considered safe for the environment. As plants contain great range of bio-active agents, growth regulation properties etc. Due to easy availability, low budget, target specific, less environmental impact, easily biodegradable, the interest in developing plant origin insecticides as an alternative to synthetic insecticides has attracted great attention.

In recent years, due to concerned knowledge regarding health and hygiene issues, the collaboration of medical personnel and textile chemistry scientists has led to evolution of functional applications for textiles. Functionality means giving protection from something which is desirable. Mosquito repellent textiles are one such textile products which protects the body from bites of mosquitoes. In textiles, durability is a major issue. To impart this characteristic, a finish of mosquito repellent agent from plant origin was used on $100 \%$ cotton fabric through microencapsulation technique. So keeping this in mind, the present work has been planned with the objective i.e. to test the efficacy and durability of microencapsulated finished cotton fabric samples.

\section{MATERIALS AND METHODS}

Selection and procurement of raw materials and auxiliaries: $100 \%$ woven cotton commonly used by consumers for apparels was selected and procured from market of Hisar city, Haryana state. Marigold flowers and nirgundi leaves were used as having mosquito repellency properties. Different eco-friendly and laboratory grade auxiliaries were selected for the 
study on the basis of easy availability and cost effectiveness i.e. gum acacia, gelatin, acetic acid, sodium hydroxide, ethanol, methanol, formaldehyde, silicon softener and citric acid were used. All were used. Some in preparation of microcapsules as per section 2.3 and another during application of finish on fabric as per section 2.4. Ratios are also mentioned in sections.

Preparation of selected fabric and plants material: Americos amylase 543 for desizing, Palkoscour APCL enzyme for scouring and Peroxyme for bleaching of fabric were used.

The collected fresh petals of marigold and leaves of nirgundi were washed and allowed to dry in shade to avoid breakdown of important compounds. Dried petals of marigold and leaves of nirgundi were ground in grinder and mixer and the powder was sieved to remove the dirt and unkind particles. The dry powders were subjected to methanol extraction using soxhlet process. Preparation of microcapsule gel: For preparation of padding bath, microcapsule gel was prepared with plant extract, gum and gelatin. $12 \mathrm{~g}$ of gelatin was dissolved in $25 \mathrm{ml}$ warm water and stirred with high speed stirrer for 10 minutes; $10 \mathrm{~g}$ of extract was added to the solution of gelatin during stirring at $40^{\circ} \mathrm{C}$ temperature of bath; $12 \mathrm{~g}$ of gum acacia was dissolved in $25 \mathrm{ml}$ warm water separately and the solution was added to gelatin and plant extract solution under stirring condition. The $\mathrm{pH}$ of the solution was decreased to 4.5 by addition of dilute acetic acid. The solution was stirred at high speed for 20 minutes and the temperature was lowered to $5^{0} \mathrm{C}$ for gel formation. Then the $\mathrm{pH}$ was increased to 8.5 using sodium hydroxide solution to form microcapsules. $1 \mathrm{ml}$ of alcoholic formalin $(17 \mathrm{ml}$ ethanol $+83 \mathrm{ml}$ formaldehyde in $100 \mathrm{ml}$ water) was added to the formed capsules for stabilization.

Application of mosquito repellent finish on fabric: Microcapsules were applied on fabric using coacervation technique of microencapsulation through pad-dry-cure method. $40 \mathrm{~g} / \mathrm{l}$ microcapsule gel, $3 \mathrm{~g} / 1$ silicon softener, $10 \mathrm{~g} / \mathrm{l}$ citric acid as binder was mixed in 1:20 Material to Liquor Ratio (MLR) MLR and fabric was immersed for 20 minutes. Padding was done in padding mangle at $2.7 \mathrm{~kg}$ pressure or rollers and fabric was dried in preheated oven at $80^{\circ} \mathrm{C}$ for 5 minutes and cured at $120^{\circ} \mathrm{C}$ for 60 seconds.

Efficacy assessment of finish: The finished (fabric obtained after applying finish on it) fabric was evaluated against mosquito repellency by specially designed modified cage method (Fig. 1). Work was done in insectary of microbiology, National Institute of Malaria Research (NIMR), New Delhi.

Mosquito rearing: Mosquitoes reared in laboratory under controlled conditions i.e. $28 \pm 2{ }^{\circ} \mathrm{C}$ temperature with 60 to $70 \%$ RH. Anopheles Stephensi female mosquitoes were collected during the evening hours in specially designed organdie fabric constructed cage measuring $12 " \times 12 " \times 12$ ".
Resin (wet kishmish) as food was placed inside the cage and $10 \%$ glucose wet pad on upper facets of the cage were kept overnight. The females hatched two days after they fed. Hatched larvae was filtered and placed in a white coated tray having boiled water at normal temperature and added a pinch of fish food (tetra bits/aquaricare) in that tray. Larvae were shifted in two more trays for better growth. Whole procedure was repeated until the pupae bent and left their outer skin in water. Collected the pupae and placed the beaker in an empty cage provided with resin and glucose. $\mathrm{Pu}-$ pae were allowed to emerge to adults for 2-3 days.

Repellency behavioral test Mosquito repellency assessment test: Laboratory tests were performed during daylight to evaluate the efficiency of repellency activity and each test was replicated three times. Mosquitoes were deprived/starved of all nutrition and water for a minimum of four hours before exposure. For conducting experiment, two controlled samples were hung on the opposite facets of an empty cage and two finished samples on another opposite facets of that cage. Upper facet was used for observing the mosquitoes (specimens). 50 mosquitoes were exposed in each cage. Number of mosquitoes on controlled and finished samples were noted down at every 15 minutes of interval for 60 minutes and calculated as per equation 1 .

Equation 1: Mosquito Repellency (\%) = (Number of specimen on controlled sample / Total exposed specimen in the cage) $\times 100 \quad$ Eq........1

Durability assessment of finish: Assessment of durability of finished cotton samples to washing as per the recommendation of IS: 3361-1979 and sun-drying was tested using IS:686-1985 standard test method in the month of June (temperature $45 \pm 2^{\circ} \mathrm{C}$ ). Observation was taken after 60 minutes. Number of mosquitoes settled on samples were noted down after 60 minutes.

\section{RESULTS}

Efficacy assessment of finishAfter applying finish on fabric samples, effectiveness was evaluated: The mosquito repellency in terms of repelled mosquitoes from the finished samples and settled on the controlled samples. As mention in section 2.5.b, control as well as finished samples were hung in the same cage for comparison because out of 50 mosquitoes (in each cage) some were settled on finished samples and rest were on controlled one as clear from table 1.The data related to efficacy assessment against mosquitoes is presented in Table 1.It is clear from Table 1 that with marigold (petals) extract, repellency was 88 to $96 \%$ from 15 to 60 minutes whereas with nirgundi (leaves) extract, repellency observed from 88 to $94 \%$.

Durability assessment of finish: The mosquito repellency durability to washing and sun drying of finished fabric is of considerable importance to the consumers for longer life of repellency. The data 
Table 1. Efficacy of mosquito repellent finish. $n=50$

\begin{tabular}{|c|c|c|c|c|c|c|}
\hline \multirow{3}{*}{$\begin{array}{c}\text { Time of observation } \\
\text { (mins) }\end{array}$} & & & \multicolumn{3}{|c|}{ Extracts } & \multirow{3}{*}{ Repellency (\%) } \\
\hline & \multicolumn{2}{|c|}{ Marigold (petals) } & \multirow{2}{*}{$\begin{array}{c}\text { Repellency } \\
\text { (\%) }\end{array}$} & \multicolumn{2}{|c|}{ Nirgundi (leaves) } & \\
\hline & $\mathrm{C}$ & $\mathbf{F}$ & & $\mathbf{C}$ & $\mathbf{F}$ & \\
\hline 15 & 44 & 6 & 88 & 44 & 6 & 88 \\
\hline 30 & 46 & 4 & 92 & 44 & 6 & 88 \\
\hline 45 & 46 & 4 & 92 & 46 & 4 & 92 \\
\hline 60 & 48 & 2 & 96 & 47 & 3 & 94 \\
\hline
\end{tabular}

C-- Number of mosquitoes settled on controlled sample, F-- Number of mosquitoes settled on finished sample, $\mathrm{n}=$ no. of mosquitoes exposed in each cage

Table 2. Durability of finish after washings.

\begin{tabular}{lcc}
\hline Extracts & Washing cycles & Repellency (\%) \\
\hline \multirow{3}{*}{ Marigold (petals) } & 0 & 96 \\
& 5 & 82 \\
& 10 & 70 \\
& 15 & 56 \\
\hline \multirow{2}{*}{ Nirgundi (leaves) } & 0 & 94 \\
& 5 & 80 \\
& 10 & 66 \\
\hline
\end{tabular}

0- finished control sample (without washing), one wash cycle- 45 minutes, $n=$ no. of mosquitoes exposed in each cage

Table 3. Durability of finish after sun-drying. $n=50$

\begin{tabular}{lcc}
\hline Extracts & No. of hours & Repellency (\%) \\
\hline \multirow{2}{*}{ Marigold (petals) } & 0 & 96 \\
& 1 & 78 \\
& 2 & 64 \\
& 3 & 56 \\
\hline Nirgundi (leaves) & 0 & 94 \\
& 1 & 72 \\
& 2 & 62 \\
\hline
\end{tabular}

0 - finished control sample (without sun-drying), $n=$ no. of mosquitoes exposed in each cage

related to durability of finish is presented in Table 2 and 3 .

Durability to washing: Finished samples were assessed for repellency of mosquitoes after washing on the basis of laboratory cage method. It is evident from Table 2 that with both extracts, mosquito repellent finish was durable up to 15 wash cycles. 82,70 and 56 $\%$ repellency observed after application of marigold (petals) extract whereas with application of nirgundi (leaves) extract, 80, 66 and $54 \%$ repellency was observed after 5, 10 and 15 wash cycles respectively.

Durability to sun-drying: Data reveals that (Table 3) mosquito repellency of finish was durable till 3 hours of sun drying using both plant extracts.

Repellency of finish with marigold (petals) extract was

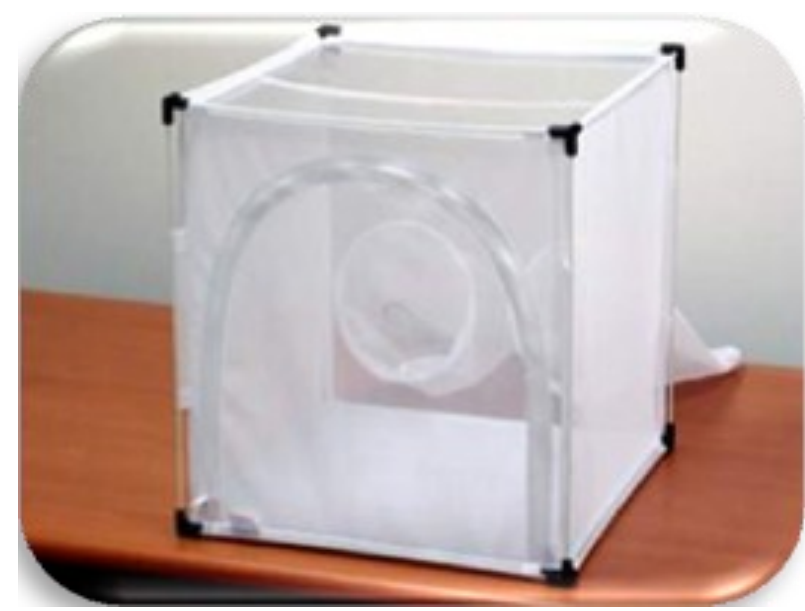

Fig.1. Modified cage for testing efficacy and durability of finish.

observed 78, 64 and 56\% after exposure in sun for 1, 2 and 3 hours respectively whereas with nirgundi (leaves) extract repellency was observed 72, 62 and 52 $\%$ after 1, 2 and 3 hours respectively.

\section{DISCUSSION}

Preparation of microcapsule gel and application on cotton fabric: Gum acacia and gelatin were used as wall materials and extracts as core materials for preparation of microcapsule gel using complex coacervation technique of microencapsulation. For preparing microcapsule gel, $40^{\circ} \mathrm{C}$ temperature of bath used along with 4.5 (initial $\mathrm{pH}$ ) of both extracts and 7.0 (final $\mathrm{pH}$ ) for marigold (petals) whereas 8.0 (final $\mathrm{pH}$ ) for nirgundi (leaves) extract were used. The proportion of microcapsule gel:softener: binder i.e. 40:3:10 g/1 for cotton was used for 20 minutes treatment/process time keeping MLR 1:20. Finished fabric samples were passed between the rollers of the pneumatic padding mangle at a pressure of $2.7 \mathrm{~kg}$ and samples were dried at $80^{\circ} \mathrm{C}$ temperature for 5 minutes and cured at $120^{\circ} \mathrm{C}$ for 60 seconds.

Ramya and Maheshwari (2014) used methanolic Andrographispaniculata plant extract as core material for developing microcapsules with sodium alginate and calcium chloride as wall materials. The microcapsulaes were obtained by decantation and repeated washing 
with isopryl alcohol followed by drying at $45^{\circ} \mathrm{C}$ for 12 hrs. $8 \%$ citric acid as binder was used for finishing on the fabrics. Specoset al. (2010) supported the results that $40^{\circ} \mathrm{C}$ temperature is best suitable for the microcapsule preparation. Gelatin, gum arabic and lemon essential oil were used for preparing microcapsules. Sukumar and Lakshmikantha (2010) reported that microcapsules were formed at initial $\mathrm{pH}$ range from 4.0-4.5 and final $\mathrm{pH}$ at 9.0.Ganesan et al. (2012) used $60 \mathrm{~g} / \mathrm{l}$ microcapsule gel for padding bath. Sumathiet al. (2015) applied microcapsules for combination of green tea, neem and aero root for one meter organic cotton fabric using $8 \%$ citric acid as binder for 30 minutes under $50^{\circ} \mathrm{C}$ temperature. Ramasamy et al. (2014) developed cotton fabric as mosquito repellence using $V$. negundo plant extract for 20 minutes.Udakheet al. (2014) carried out a study on microencapsulated citronella, lavender and eucalyptus oil against larvae carpet beetle on wool fabric for 15 minutes and fabric was padded and dried at $100^{\circ} \mathrm{C}$ and cured at $130^{\circ} \mathrm{C}$ for 2 minutes.

Efficacy assessment of finished fabric: Results in Table 1 show that cotton fabric samples finished with marigold (petals) extract showed maximum repellency ( 88 to $96 \%$ ) between 15 to 60 minutes observation time followed by samples finished with nirgundi (leaves) extract. It may be due to less or no abrasion, resulting into less or no controlled release of active compounds. Nirgundi (leaves) applied on cotton showed 92 to $96 \%$ repellency between 15 to 60 minutes time interval. Ramya and Maheshwari (2014) supported the results as the samples finished by Andrographis paniculata using microencapsulation technique showed $94 \%$ efficiency. after 30 minutes.

Durability assessment of finished fabric: Mosquito repellency durability is an important factor to be considered for plant extracts finished fabric. The mosquito repellency durability was assessed after washing and sun drying. It was noticed that durability of the fabricfinished with both plant extracts gradually decreased after exposure of finished fabric to different agencies. Repellency of mosquitoes was highest after 5 wash cycles in microencapsulated fabric finished with marigold (petals) extract as compared to nirgundi (leaves) extractfinished fabric. Mosquito repellent finish was durable till 15 wash cycles and decreased after every wash cycle. It may be due to the reason that repeated washing may cause the removal of plant extracts and other auxiliaries bonded with fabric structure. According to World Health Organization, if any mosquito repellent finish given to any textile material declines below $50 \%$, finish is not acceptable. Maximum repellency of both extracts finished cotton fabric was found after 3 hours exposure in sun. It may be due to an interaction between the hydrocarbon, oxide of nitrogen and oxygen that caused release of core material. Yuvasriet al. (2016) also interpreted the results of microencapsulated lemon grass oil on mercerized cotton fabric which exhibited maximum of $60 \%$ repellency in 5 minutes followed by lavender oil and thyme oil but the efficiency reduced to $10 \%$ after 3 hand washes.

\section{Conclusion}

Marigold (petals) extract finished fabric have been found to have better mosquito repellent property of 96 $\%$ by using complex coacervation technique of microencapsulation as compared to nirgundi (leaves) extract applied fabric i.e. $94 \%$. Although repellency efficacy difference was less. But durability in terms of washing and sun-drying was found much better of marigold (petals) extract applied fabric. Microencapsulation technique helps in control slow release of core material (extracts) with friction and temperature. Thus, it is the technique can be used on various textile products in industries to protect the well being from mosquito bites for probably longer time.

\section{REFERENCES}

Ganesan, P., Selvi, C.T. and Ramachandran, T. (2012). Microencapsulation of copper enriched herbals for curative garments. Indian Journal of Traditional Knowledge. 11 (3):532-536.

Gnanasalomi, D.V. and Gnanadoss, V.J. (2013). Laccases from fungi and their applications: recent developments. Asian Journal of Experimental Biology Sciences. 4 (4):581-590.

Karolia, A. and Mendapara, S. (2007). Imparting antimicrobial and fragrance finish on cotton using chitosan with silicon softener. Indian Journal of Textile and Fiber Research. 32(3):99-104.

Moustafa, M.G. and Fahmy, H.M. (2011). Multifunctional finish and cotton cellulose fabric. Carbohydrate Polymer. 86:625-629.

Rajendran, R., Sundram, K., Radhar, R. and Rajapriya. (2011). Bioscouring of cotton fabrics using pectinase enzyme: Its optimization and comparison with conventional scouring process. Pakistan Journal of Biological Sciences. 14:519-525.

Ramasamy, R., Raja, R. and Velmurugan, R. (2014). Development of mosquito repellent fabrics using vitex negundo loaded nanoparticles. Malaya Journal of Bio-sciences. 1(1):19-23.

Ramya, K. and Maheshwari, V. (2014). Development of eco friendly mosquito repellent fabric finished with Andrographispaniculata plant extracts. International Journal of Pharmaceutical Sciences. 6(5):115-117.

Specos, M.M., Garcia, J., Tornesello, J., Marino, P., Delle V.M., Tesoriero, M.D. and Hermida, L. (2010). Microencapsulated citronella oil for mosquito repellent finishing of cotton textiles. Transactions of the Royal Society of Tropical Medicine and Hygiene. 104(10):653658.

Sukumar, N. and Lakshmikantha, C.B. (2010). Methods of encapsulation and their evaluation of the natural aromatic oils in textile material. Indian Journal of Applied Sciences. 56(11):56-69.

Sumathi, S., Thomas, A. and Wesely, E.G. (2015). Study on 
Mamta Rana et al. / J. Appl. \& Nat. Sci. 9 (4): 2127 - 2131 (2017)

antimicrobial activity of organic cotton fabric treated with microencapsulated herbal extract. International Journal of Biological and Pharmaceutical Research. 6 (4):259-263.

Vasugi, R.N., Prabha, R. and Kanimozhi, M. (2010). Effect of mosquito repellent finish on cotton fabric. The Textile Magazine. 21(7):85-90.

Vigneshwaran, C., Ananthasubramanian, M. and Anbumani, N. (2013). Effect of sonication on bio-scouring of organic cotton through mixed enzymatic system-neural network approach. Indian Journal of Fiber and Textile Research.38(3):44-56.

WHO (1996). Testing of Insecticides.

Yuvasri, V., Devi, A.C. and Leela, K. (2016). A comparative study on microencapsulated essential oils for mosquito repellent finished cotton fabrics. Journal of Medical, Pharmaceutical and Allied Sciences.9:161-176. 